\title{
Instrument-assisted Soft Tissue Mobilization: Effects on the Properties of Human Plantar Flexors
}

Authors

Affiliations

\section{J. P. Vardiman' ${ }^{1}$, J. Siedlik ${ }^{1}$, T. Herda', W. Hawkins ${ }^{1}$, M. Cooper², Z. A. Graham¹, J. Deckert ${ }^{1}$, P. Gallagher}

${ }^{1}$ Health, Sport and Exercise Science, University of Kansas, Lawrence, United States

${ }^{2}$ Biomedical Science, University Kansas Medical Center, Kansas City, United States
Key words

muscle-tendon stiffness

inflammatory response

injury

therapeutic modality

accepted after revision

May 28, 2014

Bibliography

DOI http://dx.doi.org/

10.1055/s-0034-1384543

Published online:

October 27, 2014

Int J Sports Med 2015; 36:

197-203 @ Georg Thieme

Verlag KG Stuttgart · New York

ISSN 0172-4622

\section{Correspondence}

Prof. John Phillip Vardiman

Health, Sport and Exercise

Science

University of Kansas

161- D Robinson

Lawrence 66045

United States

Tel.: + 1/785/864 0709

Fax: + 1/785/864 3343

pvardim@ku.edu

\section{Abstract}

$\nabla$

The effect of instrument-assisted soft tissue mobilization (ISTM) on passive properties and inflammation in human skeletal muscle has not been evaluated. Passive properties of muscle, inflammatory myokines and subjective reporting of functional ability were used to identify the effects of ISTM on the plantar flexors. 11 healthy men were measured for passive musculotendinous stiffness (MTS), passive range of motion (PROM), passive resistive torque (PASTQ) and maximum voluntary contraction peak torque (MVCPT) for plantar flexor muscles of the lower leg. Interleukin-6 (IL-6) and tumor necrosis fac-

\section{Introduction}

\section{$\nabla$}

According to the marketing information for Graston Technique ${ }^{\circledR}$, a form of instrument-assisted soft tissue mobilization (IASTM), more than 16000 clinicians currently employ this technique for treating soft tissue ailments [17]. This does not include the number of clinicians and alternative medicine providers utilizing other forms of IASTM techniques such as sound-assisted soft tissue mobilization (SASTM), ASTYM ${ }^{\circledR}$, GuaSha, or others. Interestingly, the ability of IASTM to ameliorate loss of function, pain and inflammation has yet to be clarified. There are several physiological hypotheses as to how soft tissue mobilization works. These include increased blood flow, increased lymphatic drainage of toxins, reduced tissue stiffness, alteration in neuromuscular activity and a decreased inflammatory response [48]. However, the current literature fails to support these claims. Recently, studies have evaluated the effects of soft tissue mobilization on the recovery of muscular attributes following eccentric exercise-induced muscle damage $[13,14]$. Interestingly, it has been demonstrated that the intensity of the compressive load and the timing of applica- tor-alpha (TNF- $\alpha$ ) were measured from muscle biopsies from the gastrocnemius, and subjective measurements of functional ability were taken using the perception of functional ability questionnaire (PFAQ). MTS, PROM, PRT and MVCPT were measured in the treatment leg (TL) and control leg $(\mathrm{CL})$ before, immediately after, $24 \mathrm{~h}$, $48 \mathrm{~h}$ and $72 \mathrm{~h}$ following IASTM. Biopsies for IL-6 and TNF- $\alpha$ and PFAQ responses were collected before as well as $24 \mathrm{~h}, 48 \mathrm{~h}$ and $72 \mathrm{~h}$ after IASTM. There were no significant differences in MTS, PROM, PASTQ MVCPT, IL- 6 and TNF- $\alpha$ between the TL or CL. A significant decrease in the perception of function and a significant increase in pain for the TL were found following IASTM.

tion following eccentric exercise may be important components for the recovery of muscle tissue [20]. Though this research provides the most recent mechanistic example of the response to soft tissue mobilization in an animal model, the physiological differences to that of human subjects may limit its clinical applicability $[11,35]$. In contrast, the research findings on IASTM often describe clinical markers such as range of motion (ROM) and functional measures, but are not derived from randomized controlled studies [15]. Collectively, however, it appears that soft tissue mobilization therapies may play a role in reducing inflammation [6]. The purpose of this project was to evaluate the effects of IASTM on intramuscular inflammation, pain, ROM and strength following muscle damage in a randomized controlled laboratory experiment.

\section{Materials and Methods \\ $\nabla$}

Subjects

11 healthy men (mean \pm SD age $=23 \pm 3$ years; stature $=181 \pm 7 \mathrm{~cm}$; mass $=83 \pm 11 \mathrm{~kg}$ ) volunteered for this investigation. Each participant was screened 
for current or ongoing neuromuscular diseases, musculoskeletal injuries, or skin disorders specific to the plantar flexors. Participants reported that they had neither recently taken nor were currently using non-steroidal anti-inflammatory drugs (NSAID), aspirin, or other anti-thrombotic over-the-counter or prescription medications. Participants were instructed not to participate in exercise $24 \mathrm{~h}$ prior to their first scheduled visit to the laboratory or throughout the 4 subsequent days during data collection. This study was approved by the University Institutional Review Board for Human Subjects, and all participants completed a written informed consent form and a Health \& Exercise Status Questionnaire. This study also meets the ethical standards established by the International Journal of Sports Medicine [21].

\section{Research design}

A repeated measures design was used to examine the acute effects of the IASTM on plantar flexors musculotendinous stiffness (MTS), passive range of motion (PROM), and maximal voluntary contraction peak torque (MVPT), perception of functional ability questionnaire (PFAQ) responses, and intramuscular levels of interleukin-6 (IL-6) and tumor necrosis factor- $\alpha$ (TNF- $\alpha$ ) myokines. The participants visited the laboratory 5 times. The first day included familiarization with the protocol, screening of inclusion and exclusion criteria and signing the informed consent. The second visit was within 7 days of the initial visit and was the first of 4 corresponding days of data collection. The first day of data collection included random assignment of the IASTM treatment leg (TL), muscle biopsy 1 (MB1) from the control leg (CL), pre-IASTM isokinetic assessment of the TL and $\mathrm{CL}$, the IASTM treatment protocol to the TL and the post-IASTM isokinetic assessment of the TL and CL. The post-IASTM assessments occurred immediately after the treatment. The subsequent 3 visits included muscle biopsy of the TL only and isokinetic assessment of the TL and CL. All experimental trials were performed at the same time of day $( \pm 15 \mathrm{~min})$.

\section{MTS}

Musculotendinous stiffness of the plantar flexors was quantified. MTS is the ability of the combined musculotendinous unit to prevent a change in length when force is applied [37]. This was measured using a fourth-order polynomial regression model that was fitted to the passive angle-torque curves for each subject [32]. The fourth-order polynomial model was chosen over other models (i.e., second-order polynomial and StenKnudson) based on the comparative recommendation of Nordez [32] and because the fourth-order polynomial is classically used in the literature to assess in vivo MTS $[28,29,40]$. MTS quantifies the joint angle-specific stiffness of the musculotendinous unit based on the passive angle-torque relationship. MTS was calculated for each $1^{\circ}$ increment in the passive angle-torque relationships from the neutral ankle position of $0^{\circ}$ (i.e., $90^{\circ}$ between the foot and leg) to the end of the range of motion. The ROM for each measure was determined using the position signal from the isokinetic dynamometer. The final MTS value that was calculated for the joint angles commonly achieved during both the pre- and post-treatment trials was analyzed. For example, if MTS values were obtained for a subject at $10^{\circ}, 11^{\circ}$ and $12^{\circ}$ during the pretreatment assessment, and MTS values were calculated at $10^{\circ}$, $11^{\circ}, 12^{\circ}$ and $13^{\circ}$ for the post-treatment assessment, then the values at $12^{\circ}$ were used for analysis, because this joint angle was common to both the pre- and post-treatment assessments. MTS values were calculated using the following equation [32], where $\theta$ represented the joint angle, and $m, n, o, p$, and $q$ were coefficients in the fourth-order polynomial regression model that was fit to the passive angle-torque relationship:

passive torque $=m \theta^{4}+n \theta^{3}+o \theta^{2}+p \theta+q$

MTS was subsequently calculated with the following equation [32].

$\operatorname{MTS}(\theta)=4 m \theta^{3}+3 n \theta^{2}+2 o \theta+p$

\section{PROM}

The passive range of motion (PROM) of the plantar flexors was determined for each participant during the pre- and post-treatment assessments using the isokinetic dynamometer programmed in passive mode. PROM is the measure of the terminal end of motion in a joint facilitated by passively moving the limb. This is typically determined by the patient's subjective indication of when the limbs movement becomes painful [22]. Maximum PROM was determined for each individual during the trial as the point of discomfort, but not pain, as verbally acknowledged by the subject during a passive stretch of the plantar flexors while the leg was in terminal knee extension. The dynamometer lever arm passively dorsiflexed the foot at an angular velocity of $5 \% \mathrm{~s}$ until the end range of motion. PROM was calculated as the range of motion attained from $0^{\circ}$ (neutral) to the maximum tolerable point of passive dorsiflexion. No gravity correction was performed based on the methods of Muir [30], who indicated that the foot constituted approximately $1.4 \%$ of the body's mass [50] and suggested that this mass can be considered negligible.

\section{MVPT}

To determine maximal voluntary contraction peak torque (MVPT), each participant performed two 5-s isometric MVCs of the plantar flexors at a neutral ankle joint angle $\left(0^{\circ}=90^{\circ}\right.$ between the foot and leg), while the knee joint was in terminal knee extension. The MVPT is the force produced at a specific angle in a patient's range of motion. A 2-min rest was allowed between trials. The MVPT for each trial was determined as the highest consecutive $0.25 \mathrm{~s}$ epoch. The same $0.25 \mathrm{~s}$ epoch were selected for the EMG signals to calculate the time domain estimates during the MVC trials. The mean PT value from the 2 MVC trials was used as the representative score for further analyses. The participants were instructed to give a maximum effort for each trial and strong verbal encouragement was provided by the investigators.

\section{Surface EMG}

EMG was collected to ensure all PROM assessments were passive according to Gajdosik et al. (2005). Pre-amplified bipolar, active surface EMG electrodes were placed on the medial gastrocnemius (MG) and soleus (SOL) muscles. The electrode configuration (TSD150B, Biopac Systems Inc.; Santa Barbara, California, USA) had a fixed center-to-center interelectrode distance of $20 \mathrm{~mm}$, built-in differential amplifier with a gain of 350 (nominal), input impedance of $100 \mathrm{M} \Omega$, and common mode rejection ratio of $95 \mathrm{~dB}$ (nominal). For the SOL, the electrodes were placed along the longitudinal axis of the tibia at $66 \%$ of the distance between the medial condyle of the femur and the medial malleolus. The electrodes for the MG were placed on the most prominent bulge of the muscle per the recommendations of [specify 

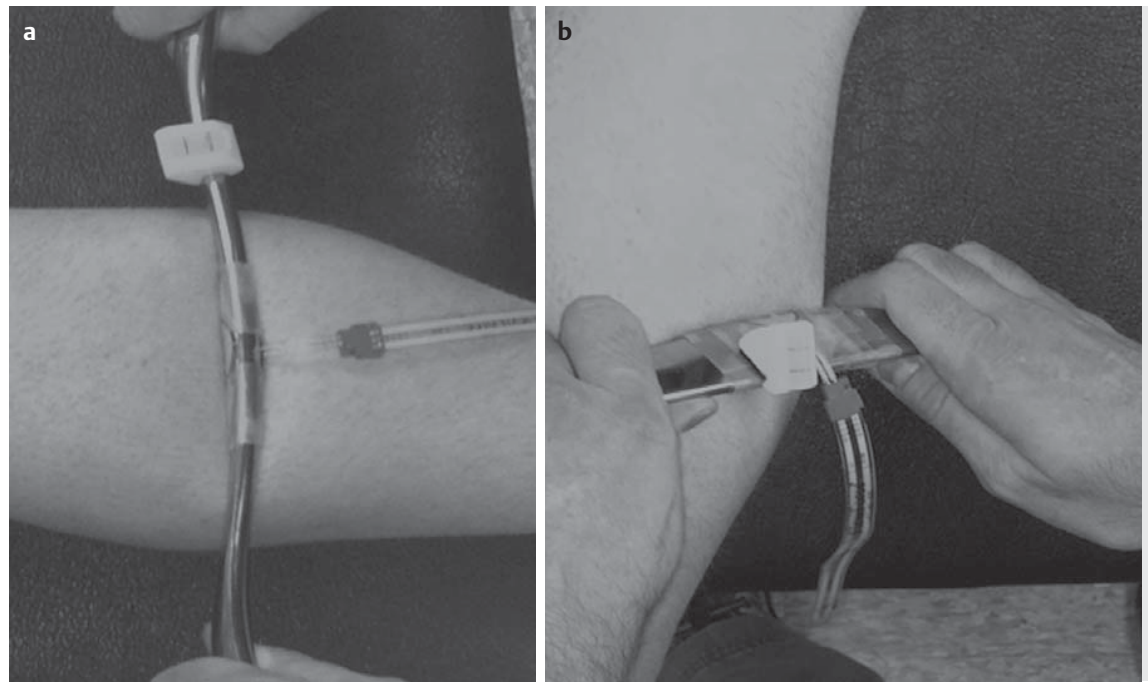

Fig. 1 a, b IASTM with level and ELF System attached to ensure consistent pressure and angles.

Table 1 Perception of Functional Ability Questionnaire (PFAQ) scores.

\begin{tabular}{|c|c|c|c|c|}
\hline & $\begin{array}{c}\text { Pre } \\
\text { Perception value }\end{array}$ & $\begin{array}{c}24 \mathrm{~h} \\
\text { Perception value }\end{array}$ & $\begin{array}{c}48 \mathrm{~h} \\
\text { Perception value }\end{array}$ & $\begin{array}{c}72 \mathrm{~h} \\
\text { Perception value }\end{array}$ \\
\hline overall physical health & $8.09 \pm 1.50$ & $7.64 \pm 1.43$ & $7.27 \pm 1.54$ & $7.27 \pm 1.42$ \\
\hline overall muscle flexibility & $5.09 \pm 1.98$ & $5.36 \pm 2.06$ & $5.36 \pm 2.01$ & $5.55 \pm 2.15$ \\
\hline treated body part ROM & $5.45 \pm 2.35$ & $5.45 \pm 1.72$ & $5.55 \pm 2.10$ & $5.64 \pm 2.31$ \\
\hline overall muscle strength & $5.82 \pm 1.11$ & $6.27 \pm 1.42$ & $6.45 \pm 1.23$ & $6.64 \pm 1.37$ \\
\hline treated body part strength & $6.27 \pm 1.54$ & $6.27 \pm 1.71$ & $6.27 \pm 1.29$ & $6.36 \pm 1.61$ \\
\hline treated body part pain & $0.27 \pm 0.62$ & $1.64 \pm 1.43^{*}$ & $1.55 \pm 1.78^{*}$ & $1.64 \pm 2.10^{*}$ \\
\hline treated body part function & $1.55 \pm 2.68$ & $2.55 \pm 2.97$ & $2.55 \pm 2.90$ & $2.36 \pm 2.99$ \\
\hline treated body part ability to perform ADL & $1.09 \pm 2.35$ & $1.80 \pm 2.32^{*}$ & $1.45 \pm 1.67^{*}$ & $1.55 \pm 2.06^{*}$ \\
\hline
\end{tabular}

author] [23]. A single pre-gelled, disposable electrode (Ag- $\mathrm{Ag} \mathrm{Cl}$, Quinton Quick Prep, Quinton Instruments Co., Bothell, Washington, USA) was placed on the spinous process of the seventh cervical vertebrae to serve as a reference electrode. To reduce interelectrode impedance and increase the signal-to-noise ratio, local areas of the skin were shaved, lightly abraded, and cleaned with isopropyl alcohol prior to placement of the electrodes.

\section{Signal processing}

The EMG and torque signals were recorded simultaneously with a Biopac data acquisition system (MP150WSW, Biopac Systems, Inc. Santa Barbara, California, USA) during each MVPT and PROM assessment. The for torque (Nm), signals from the dynamometer and EMG $(\mu \mathrm{V})$ signals were sampled at $2 \mathrm{kHz}$ and recorded from the SOL and MG. All signals were stored on a personal computer (Dell Inspiron 8200, Dell, Inc., Round Rock, Texas, USA), and processing was completed off-line using custom written software (LabVIEW v 7.1, National Instruments, Austin, Texas, USA). The EMG signals were digitally filtered (zero-phase fourth-order Butterworth filter) with a pass band of 10-500. The torque signal was low-pass filtered with a $10 \mathrm{~Hz}$ cutoff (zero-phase fourthorder Butterworth filter). All subsequent analyses were performed on the filtered signals.

\section{PFAQ}

The Perception of Functional Ability Questionnaire (PFAQ) was developed by panel of physicians, athletic trainers and patients. 6 critical domains were identified for the assessment of functional ability during a functional task: physical health, flexibility, muscular strength, pain, restriction of sport, skill and activity of daily living (ADL) performance. To assess the 6 domains, an 8 -question questionnaire with associated visual analogue scale from $0-10$ was developed. The PFAQ was evaluated for testretest reliability using 60 college-aged students following procedures described by Levine [25]. Internal consistency was assessed for all items collectively using Chronbach's alpha ( $=0.856$ ), with a score of 0.8 being considered good and 0.9 excellent. Each participant completed the PFAQ prior to the muscle biopsy and isokinetic testing on each of the testing days.

\section{IASTM protocol}

The IASTM protocol was administered by a certified athletic trainer who with over 13 years of experience and who had completed the Advanced Upper/Lower Quadrant Training in IASTM, Module 2 (Graston Technique ${ }^{\circledR}$, Indianapolis, IN). On day 1, subjects underwent the IASTM protocol on the plantar flexors of the randomly assigned TL. The IASTM was a $7-8 \mathrm{~min}$, soft-tissue mobilization protocol using one convex shaped ( $\bullet$ Fig. 1a) and one concave shaped ( $\bullet$ Fig. 1b) stainless steel instrument designed for IASTM (Graston Technique, Indianapolis, IN). The plantar flexors of the TL were divided into 4 treatment sections. Each section received 3 sets of 7 strokes in both proximal and distal directions. A bubble level was applied to both instruments to provide the clinician with a consistent treatment angle of $45^{\circ}$. Flexiforce-Economical Load and Force pressure sensors (ELFTM) (Tekscan, South Boston, MA) were applied to the instrument's treatment surface to ensure standardized treatment pressures throughout the protocol. Measures of peak and mean pressure for each of the 4 treatment quadrants were recorded and shown in $\odot$ Table 1. 


\section{Muscle biopsy}

Following collection of ROM, PT and SL1-RM measures, percutaneous muscle biopsies $(\sim 100 \mathrm{mg})$ [1] were taken from the gastrocnemius of each subject of the TL and CL on days 4 and 5. All biopsies were obtained from the mid-belly region of the muscle, and each biopsy was $2-3 \mathrm{~cm}$ proximal from the previous site and within the region treated by IASTM. Each subject received standard antiseptic application to each biopsy site followed by an injection of $3 \mathrm{cc}$ of local anesthetic ( $2 \%$ lidocaine) to each biopsy site. The subject then rested for $5 \mathrm{~min}$ to ensure that the area was sufficiently anesthetized. An incision approximately $0.5 \mathrm{~cm}$ wide and $1 \mathrm{~cm}$ deep was then made using a scalpel (\#11 Blade) approximately $6-8 \mathrm{~cm}$ from the joint line of the knee. All samples were then placed in liquid nitrogen and stored at $-80^{\circ} \mathrm{C}$ until analysis.

\section{Muscle processing}

Approximately $20 \mathrm{mg}$ of each muscle sample was homogenized in extraction buffer (Biosource; Carlsbad, CA) using a glass-onglass tissue grinder. Homogenized samples were centrifuged at $4^{\circ} \mathrm{C}$ at $3000 \mathrm{rpm}$ for $4 \mathrm{~min}$. For determining total protein, supernatant was separated from the pellet and the sample was diluted $(1: 1000)$ in preparation for analysis using a bicinchoninic acid (BCA) protein assay (Pierce; Rockford, IL). All samples were measured in triplicate using a Synergy microplate reader (BioTek, Winooski, VT) at $450 \mathrm{~nm}$.

\section{Western blotting}

Muscle samples were diluted with $5 \mathrm{x}$ buffer (IL-6) or $1 \mathrm{x}$ buffer (TNF- $\alpha$ ) and heated for $3 \mathrm{~min}$ at $100^{\circ} \mathrm{C}$. $80 \mu \mathrm{g}$ of protein was loaded for each sample and placed on a $5 \%$ stacking and $10 \%$ separating gel at $0.05 \mathrm{~mA}$ for $1 \mathrm{~h}$. Proteins were transferred to hydrophobic polyvinylidene difluoride (PVDF) membranes at $0.20 \mathrm{~mA}$ for $2 \mathrm{~h}$. Membranes were blocked for $1 \mathrm{~h}$ in a Tris-buffered saline with $5 \%$ nonfat dry milk on a rocker at room temperature. Membranes were then incubated at $4{ }^{\circ} \mathrm{C}$ on a plate rocker overnight in a 1:1000 IL-6 (Cell Signaling Technology, Inc., Beverly, MA) or TNF- $\alpha$ antibody (Cell Signaling Technology, Inc., Beverly, MA) which was normalized to tubulin (Cell Signaling Technology, Inc., Beverly, MA) in TBST and $1 \%$ nonfat dry milk solution. Following the overnight incubation, membranes were rinsed 3 times for $5 \mathrm{~min}$ in TBST. Membranes were incubated in horseradish peroxidase conjugated secondary antibody for an hour and once again rinsed 3 times for $5 \mathrm{~min}$ in TBST. Membranes were then incubated in chemiluminescence. IL-6 and TNF- $\alpha$ (Santa Cruz Biotechnology, Santa Cruz, CA) protein bands were then visualized and quantified using densitometry (AlphaView ${ }^{\circledR}$ FluorChemHD2 v.3.4.0.0, Protein Simple, Santa Clara, CA).

\section{Statistical analyses}

3 separate $2 \times 5$ repeated measures ANOVAs [group (CL vs. TL) $\times$ time (pre-IASTM, post-IASTM, day 2, 3, and 4)] were used to analyze MTS, PROM, and MVPT data. 3 separate one-way repeated measures ANOVAs were used to analyze PFAQ, IL-6 and TNF- $\alpha$. When appropriate, follow-up analyses were performed using paired samples t-tests and with Bonferroni's corrections.

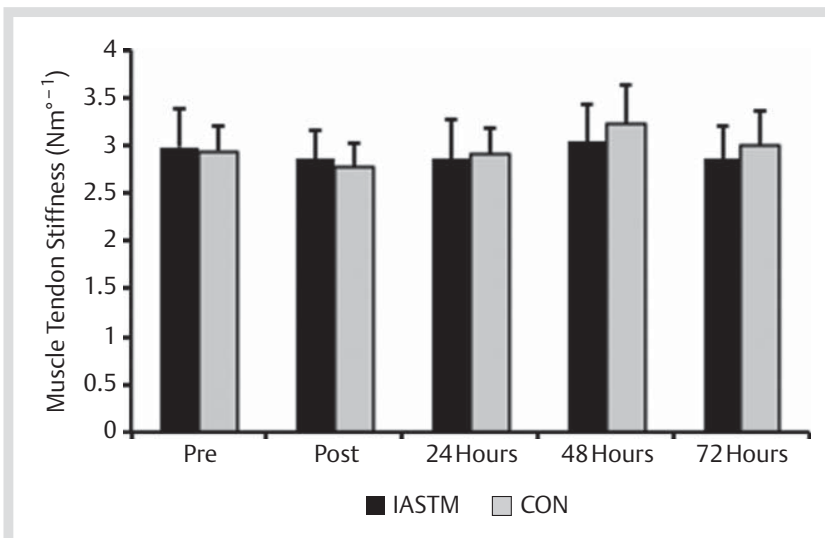

Fig. 2 Muscle tendon stiffness.

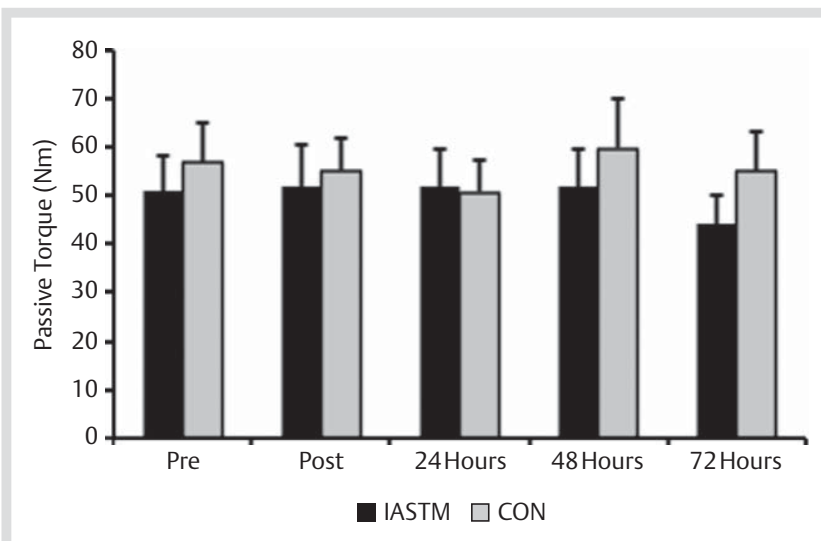

Fig. 3 Passive ROM.

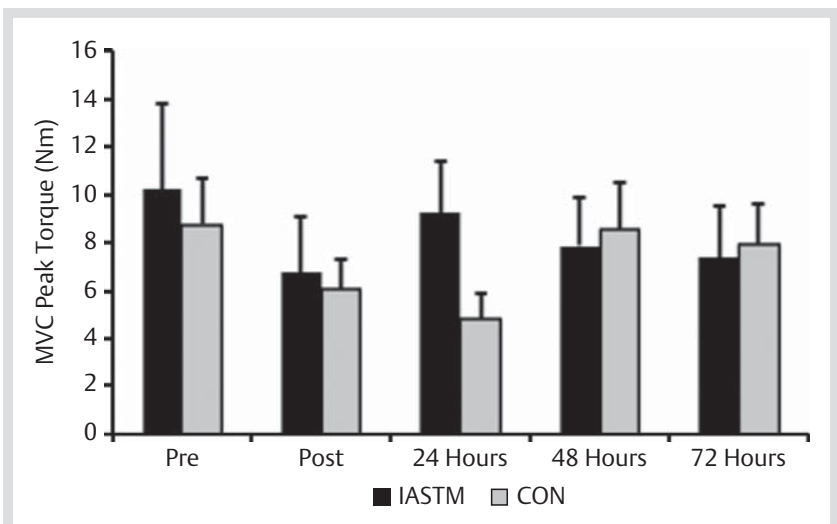

Fig. 4 Maximum voluntary peak torque.

\section{Results}

$\nabla$

MTS

For MTS, there were no significant two-way interactions (time $\times$ treatment, $\mathrm{P}=0.92$ ) and no significant main effects for time $(P=0.63)$ or treatment $(P=0.89)(\diamond$ Fig. 2$)$.

\section{PROM}

For PROM, there were no significant two-way interactions (time $\times$ treatment, $\mathrm{P}=0.78$ ) and no significant main effects for time $(P=0.11)$ or treatment $(P=0.64)(\odot$ Fig. 3 ). 
Table 2 Pressure (N) of IASTM treatment by quadrant. Values are presented as $M E A N \pm S D$.

\begin{tabular}{llllll} 
& \multicolumn{4}{c}{ Quadrant peak force } \\
& I & II & III & IV \\
Scanner & $4.68 \pm 1.65$ & $6.61 \pm 2.64$ & $8.32 \pm 4.64$ & $9.07 \pm 4.96$ \\
\hline Bar & $4.85 \pm 1.80$ & $5.29 \pm 2.50$ & $8.21 \pm 4.65$ & $8.21 \pm 3.57$ \\
& \multicolumn{4}{c}{ Quadrant mean force } \\
& I & II & III & IV \\
Scanner & $2.63 \pm 1.00$ & $3.17 \pm 1.37$ & $3.84 \pm 2.65$ & $4.47 \pm 2.36$ \\
Bar & $2.77 \pm 1.14$ & $2.41 \pm 1.22$ & $3.14 \pm 1.49$ & $4.07 \pm 1.42$ \\
\hline
\end{tabular}

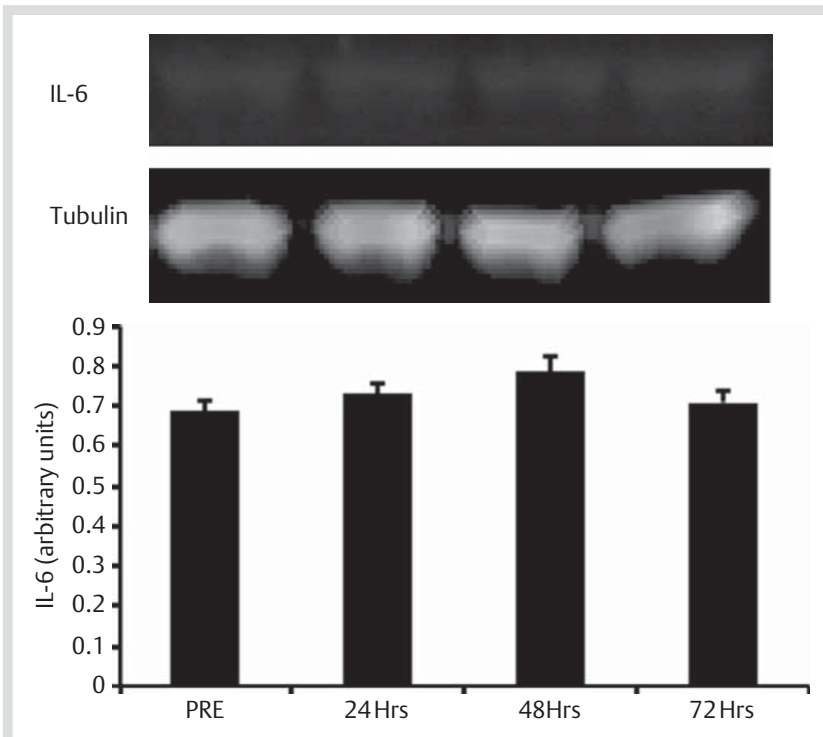

Fig. 5 IL-6 levels normalized to tubulin.

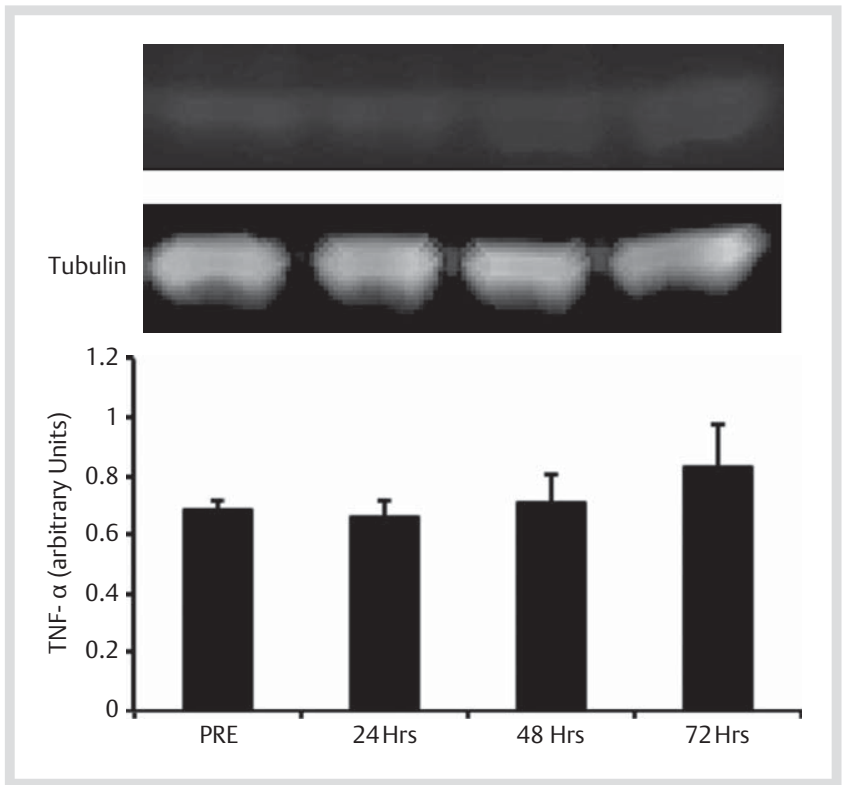

Fig. 6 TNF- $\alpha$ levels normalized to tubulin.

\section{MVPT}

For MVPT, there were no significant two-way interactions (time $\times$ treatment, $\mathrm{P}=0.25$ ) and no significant main effects for time $(P=0.6)$ or treatment $(P=0.45)(\diamond$ Fig. 4$)$.

\section{PFAQ}

A significant difference was found for time for the subjective measures of the treated body part's ability to perform activities of daily living $(\mathrm{P}=0.02)$ and pain $(\mathrm{P}=0.006)$. Subjective measures of the treated body part's ability to perform activities of daily living significantly changed from baseline measures at $24 \mathrm{~h}$ $(\mathrm{P}=0.045)$ and $48 \mathrm{~h}(\mathrm{P}=0.03)$ following IASTM. Subjective measures of pain significantly increased from baseline measures at 24h ( $\mathrm{P}=0.005), 48 \mathrm{~h}(\mathrm{P}=0.20)$ and $72 \mathrm{~h}(\mathrm{P}=0.03)$ following IASTM. No significant differences were found for any of the reported measures of the PFAQ following IASTM over time ( 0 Table 2).

\section{IL-6}

For IL-6, there were no significant differences $(P=0.82)$ at any point in time following IASTM ( $\bullet$ Fig. 5 ).

\section{TNF- $\alpha$}

For TNF- $\alpha$, there were no significant differences $(P=0.68)$ at any point in time following IASTM ( $\bullet$ Fig. 6 ).

\section{Discussion}

$\nabla$

The present study indicates that IASTM does not change the passive properties, MTS, PROM or MVPT, in healthy human skeletal muscle. To our knowledge, our data represent the only evaluation of passive muscle properties and subjective measures of function following IASTM performed on healthy human skeletal muscle. The majority of studies examining the effects of soft tissue mobilization on muscle strength show no benefits $[3,43,51]$. These data are contrary to previous research in an in-vivo animal model indicating that viscoelastic properties are effected acutely and accumulatively through massage-like loads [7]. Davidson et al. (1997) and Loghmani and Warden (2009) have also previously shown a localized healing response in injured animal models $[9,26]$. To our knowledge, no studies have examined the effects of IASTM on MTS. The current data also indicate that subjective measures of the treated body part's pain and ability to perform activities of daily living decreased following IATSM. This does not align with the majority of data measuring the use of IASTM in clinical pathology case studies. These data indicate a perceived decrease in pain measures and a perceived increase in functional ability $[34,49]$. Gehlsen et al. (1999) indicate that the application of heavy pressure with the instruments is needed for promoting the induction of the healing process [14]. This is contrary to the techniques currently taught during IASTM courses. Instructors encourage appropriate clinical pressure that is tolerable to the patient and that will not cause severe pain or bruising to the treatment area [17].

The current data indicate that IASTM using appropriate clinical pressure with the instrument held within the accepted treatment angle does not cause muscle damage or initiate the inflammatory process in healthy human muscle tissue. Additionally, it indicates that this specific IASTM treatment did not change MTS, increase PROM or change MVPT values following treatment in healthy human muscle tissue. The physiological response to specific treatment pressure(s) and treatment angle(s) are currently unknown. Likewise, the differences in the physiological response to IASTM in healthy and injured human soft tissue are currently unknown. 
Manual therapy techniques, such as massage, have been studied for efficacy in the clinical treatment of muscle $[2,13,19,20]$. Specifically, studies have measured how manual mobilization of soft tissue can increase function [12], aid in recovery following exercise [43] and decrease subjective pain measures [19,20, $39,43]$. Loss of function in patients suffering from muscle damage is commonly present alongside decreases in range of motion and strength. Changes in range of motion are often associated with the accumulation of extracellular fluids and increased pain with movement $[18,33,44]$. Decreases in strength following eccentric exercise damage protocols are thought to be a response from decreased excitation-contraction coupling [24], localized accumulation of immune and inflammatory markers [42] and ultra-structural changes to the contractile proteins in the muscle [36]. In the case of muscle damaged from high-intensity exercise or injury, loss of function and notable increases in pain are often a result of structural changes in the tissue $[8,31]$ and a localized inflammatory response [27], including localized influx of leukocytes that produce prostaglandins that sensitize type III and IV nerve endings [4]. This acute inflammatory response is associated with increased localized blood flow and myokine levels, including interleukin-6 (IL-6) and tumor necrosis factor- $\alpha$ $(\mathrm{TNF}-\alpha)$. Our data indicate that levels of intramuscular myokines, IL- 6 and TNF- $\alpha$, do not increase following IASTM. These data are contradictory to previous research by Crane et al.[6] evaluating the effect of massage following muscle damage protocol. While previous case studies have reported successful outcomes from the application of IASTM to clinical pathologies $[34,49]$, our data does not indicate that the neuromechanical and inflammatory properties or subjective measures of function change significantly following IASTM on healthy human skeletal muscle. It should be noted that the IASTM protocol did not follow a typical clinical pattern of warming the tissue with modalities or exercise followed by evaluating the tissue with soft tissue massage or with the instruments. Following the evaluation of tissue the clinician would use multiple instruments with multiple stroke techniques in multiple directions, including cross frictional strokes. Further evaluation of the neuromechanical and inflammatory effects of IASTM on human skeletal muscle is needed. Specifically, knowledge about how IASTM may effect skeletal muscle in patients suffering from clinical pathologies would provide clinicians with data for evidence-based therapy. Other measures used to assess function include musculotendinous stiffness (MTS), passive range of motion (PROM) and maximal voluntary contraction peak torque (MVPT). MTS is the ability of the combined musculotendinous unit to prevent a change in length when force is applied [37]. PROM is the measure of the terminal end of motion in a joint allowed by passively moving the limb. This is typically determined by the patient's subjective indication of when the limbs movement becomes painful [22]. MVPT is the force produced at a specific angle in a patient's range of motion. The force-producing capability of muscle following interventions such as static stretching [5] as well as the application of ice and heat [16] has been previously examined.

Dynamic changes, such as strength, also reportedly decreased immediately following damage and lasted approximately 10 days [46]. It has been shown previously that passive muscle properties significantly change following trauma. Neuromechanical properties such as muscle tendon stiffness (MTS), maximal voluntary contraction peak torque (MVPT), and passive range of motion (PROM) all suffer following injury [47]. Damage to skeletal muscle also results in a localized inflammatory response, an increase in localized blood flow and myokine levels, including interleukin-6 (IL-6) and tumor necrosis factor- $\alpha$ (TNF$\alpha)$ [27]. IL-6 inhibits inflammation by stimulating the production of the anti-inflammatory cytokines including IL-1ra, IL-10 and soluble TNF- $\alpha$ receptors [38].

It has been observed that the severity of symptoms, including reduction in passive range of motion (ROM), is a reflection of muscle damage. These passive changes are related to mechanical alterations [22]. Altogether, the athlete or patient will have diminished capacities of function as well as a changed perception of his or her ability to perform functional activities. A patient's perception of functional ability is associated with his or her subjective level of musculoskeletal pain [45]. Clinically, physicians use both subjective measures and objective measures of pain, muscle strength and range of motion to determine return to activity decisions [10]. The perception of reduced functional ability is associated with strength and ROM restrictions following trauma [41]. Clinicians incorporate numerous techniques and modalities as countermeasures for injury and to mitigate pain. Manual therapy techniques, such as instrument-assisted soft tissue mobilization (IASTM), are often used to address the patient's subjective complaints and objective loss of function.

\section{Acknowledgements}

We would like to thank Sami Shalhoub for his expert design of the leveling device for the IASTM instruments.

Conflict of interest: The authors have no conflict of interest to declare.

References

1 Bergstrom J. Muscle electrolytes in man determined by neutron activation analysis on needle biopsy specimens. Scand J Clin Lab Invest 1962; 14: $1-110$

2 Butterfield TA, Zhao Y, Agarwal S, Haq F, Best TM. Cyclic compressive loading facilitates recovery after eccentric exercise. Med Sci Sports Exerc 2008; 40: 1289

3 Cafarelli E, Flint $F$. The role of massage in preparation for and recovery from exercise. An overview. Sports Med 1992; 14: 1-9

4 Conceicao MS, Libardi CA, Nogueira FR, Bonganha V, Gaspari AF, Chacon-Mikahil MP, Cavaglieri CR, Madruga VA. Effects of eccentric exercise on systemic concentrations of pro- and anti-inflammatory cytokines and prostaglandin (E2): comparison between young and postmenopausal women. Eur J Appl Physiol 2012; 112: 3205-3213

5 Costa PB, Ryan ED, Herda TJ, Walter AA, Hoge KM, Cramer JT. Acute effects of passive stretching on the electromechanical delay and evoked twitch properties: a gender comparison. J Appl Biomech 2012; 28: 645-654

6 Crane JD, Ogborn DI, Cupido C, Melov S, Hubbard A, Bourgeois JM, Tarnopolsky MA. Massage therapy attenuates inflammatory signaling after exercise-induced muscle damage. Sci Translational Med 2012; 4: 1-8 (119ra113)

7 Crane JD, Ogborn DI, Cupido C, Melov S, Hubbard A, Bourgeois JM, Tarnopolsky MA. Massage therapy attenuates inflammatory signaling after exercise-induced muscle damage. Sci Translational Med 2012; 4: $119 \mathrm{ra} 113$

8 Dannecker EA, Liu Y, Rector RS, Thomas TR, Fillingim RB, Robinson ME. Sex differences in exercise-induced muscle pain and muscle damage. J Pain 2012; 13: 1242-1249

9 Davidson CJ, Ganion LR, Gehlsen GM, Verhoestra B, Roepke JE, Sevier TL. Rat tendon morphologic and functional changes resulting from soft tissue mobilization. Med Sci Sports Exerc 1997; 29: 313-319

10 Delvaux F, Rochcongar P, Bruyere O, Bourlet G, Daniel C, Diverse P, Reginster JY, Croisier JL. Return-to-play criteria after hamstring injury: actual medicine practice in professional soccer teams. Br J Sports Med 2013; 47: e3 
11 Doran P, Gannon J, O'Connell K, Ohlendieck K. Proteomic profiling of animal models mimicking skeletal muscle disorders. Proteomics Clin Appl 2007; 1: 1169-1184

12 Ebert JR, Joss B, Jardine B, Wood DJ. Randomized trial investigating the efficacy of manual lymphatic drainage to improve early outcome after total knee arthroplasty. Arch Phys Med Rehabil 2013 Epub ahead of print

13 Garrido N, Oliveira G, Mendes R, Sousa N, Sousa M. Acute effects of muscle massage previous to strength training on biochemical markers of delayed onset muscle soreness. Br J Sports Med 2013; 47: e3

14 Gehlsen GM, Ganion LR, Helfst R. Fibroblast responses to variation in soft tissue mobilization pressure. Med Sci Sports Exerc 1999; 31: $531-535$

15 George JW, Tunstall AC, Tepe RE, Skaggs CD. The effects of active release technique on hamstring flexibility: a pilot study. J Manipulative Physiol Ther 2006; 29: 224-227

16 Girard O, Bishop DJ, Racinais S. Hot conditions improve power output during repeated cycling sprints without modifying neuromuscular fatigue characteristics. Eur J Appl Physiol 2013; 113: 359-369

17 GrastonTechnique ${ }^{\circledR}$. About Graston Technique (2012). In. Internet http://www.grastontechnique.com/AboutUs.html 2012

18 Green M, Sinkus R, Gandevia S, Herbert R, Bilston L. Measuring changes in muscle stiffness after eccentric exercise using elastography. NMR Biomed 2012; 25: 852-858

19 Haas C, Butterfield TA, Abshire S, Zhao Y, Zhang X, Jarjoura D, Best TM Massage timing affects post-exercise muscle recovery and inflammation in a rabbit model. Med Sci Sports Exerc 2012

20 Haas C, Butterfield TA, Zhao Y, Zhang X, Jarjoura D, Best TM. Dosedependency of massage-like compressive loading on recovery of active muscle properties following eccentric exercise: rabbit study with clinical relevance. Br J Sports Med 2013; 47: 83-88

21 Harriss DJ, Atkinson G. Update - Ethical standards in sport and exercise science research: 2014 update. Int J Sports Med 2013; 34: 1025-1028

22 Herda TJ, Cramer JT, Ryan ED, McHugh MP, Stout JR. Acute effects of static versus dynamic stretching on isometric peak torque, electromyography, and mechanomyography of the biceps femoris muscle. J Strength Cond Res 2008; 22: 809

23 Hermens HJ, Freriks B, Disselhorst-Klug C, Rau G. Development of recommendations for SEMG sensors and sensor placement procedures. J Electromyogr Kinesiol 2000; 10: 361-374

24 Ingalls $C P$, Warren GL, Williams JH, Ward CW, Armstrong RB. E-C coupling failure in mouse EDL muscle after in vivo eccentric contractions. J Appl Physiol 1998; 85: 58-67

25 Levine DW, Simmons BP, Koris M, Daltroy L, Hohl G, Fossel A, Katz J. A self-administered questionnaire for the assessment of severity of symptoms and functional status in carpal tunnel syndrome. J Bone Joint Surg Am 1993; 75: 1585-1585

26 Loghmani MT, Warden SJ. Instrument-assisted cross-fiber massage accelerates knee ligament healing. J Orthop Sports Phys Ther 2009; 39: 506-514

27 MacIntyre DL, Sorichter S, Mair J, Berg A, McKenzie DC. Markers of inflammation and myofibrillar proteins following eccentric exercise in humans. Eur J Appl Physiol 2001; 84: 180-186

28 Magnusson SP, Simonsen EB, Aagaard P, Kjaer M. Biomechanical responses to repeated stretches in human hamstring muscle in vivo. Am J Sports Med 1996; 24: 622-628

29 Magnusson SP, Simonsen EB, Aagaard P, Sorensen H, Kjaer M. A mechanism for altered flexibility in human skeletal muscle. J Physiol 1996; 497: 291-298

30 Muir IW, Chesworth BM, Vandervoort AA. Effect of a static calf-stretching exercise on the resistive torque during passive ankle dorsiflexion in healthy subjects. J Orthop Sports Phys Ther 1999; 29: 106-113 discussion 114-105
31 Neme Ide B, Alessandro Soares Nunes L, Brenzikofer $R$, Macedo DV. Time course of muscle damage and inflammatory responses to resistance training with eccentric overload in trained individuals. Mediat Inflamm 2013 Epub 2013 Jan 22

32 Nordez A. Acute effects of static stretching on passive stiffness of the hamstring muscles calculated using different mathematical models. Clin Biomech (Bristol Avon) 2006; 7: 755-760

33 Nosaka K, Newton M, Sacco P. Delayed-onset muscle soreness does not reflect the magnitude of eccentric exercise-induced muscle damage. Scand J Med Sci Sports 2002; 12: 337-346

34 Papa JA. Conservative management of achilles tendinopathy: a case report. J Can Chiropr Assoc 2012; 56: 216-224

35 Paulsen G, Mikkelsen UR, Raastad T, Peake JM. Leucocytes, cytokines and satellite cells: what role do they play in muscle damage and regeneration following eccentric exercise? Exerc Immunol Rev 2012; 18 : 42-97

36 Peake J, Nosaka KK, Suzuki K. Characterization of inflammatory responses to eccentric exercise in humans. Exerc Immunol Rev 2005 11: 64-85

37 Pearson SJ, McMahon J. Lower limb mechanical properties: Determining factors and implications for performance. Sports Med 2012; 42: 929-940

38 Petersen AM, Pedersen BK. The anti-inflammatory effect of exercise. J Appl Physiol 2005; 98: 1154-1162

39 Preyde $M$. Effectiveness of massage therapy for subacute low-back pain: a randomized controlled trial. Can Med Assoc J 2000; 162: 1815-1820

40 Riemann BL, DeMont RG, Ryu K, Lephart SM. The effects of sex, joint angle, and the gastrocnemius muscle on passive ankle joint complex stiffness. J Athl Train 2001; 36: 369-375

41 Skaara HE, Moksnes H, Frihagen F, Stuge B. Self-reported and performance-based functional outcomes after surgical repair of proximal hamstring avulsions. Am J Sports Med 2013 Epub ahead of print

42 Takekura H, Fujinami N, Nishizawa T, Ogasawara H, Kasuga N. Eccentric exercise-induced morphological changes in the membrane systems involved in excitation-contraction coupling in rat skeletal muscle. J Physiol 2004; 533: 571-583

43 Tiidus PM, Shoemaker JK. Effleurage massage, muscle blood flow and long-term post-exercise strength recovery. Int J Sports Med 1995; 16: 478-483

44 Tufano JJ, Brown LE, Coburn JW, Tsang KK, Cazas VL, LaPorta JW. Effect of aerobic recovery intensity on delayed onset muscle soreness and strength. J Strength Cond Res 2012; 26: 2777-2782

45 Ursin $H$. Sensitization, somatization, and subjective health complaints. Int J Behav Med 1997; 4: 105-116

46 Vaczi M, Racz L, Hortobagyi T, Tihanyi J. Dynamic contractility and efficiency impairments in stretch-shortening cycle are stretch-load dependent after training-induced muscle damage. I Strength Cond Res 2012; 27: 2171-2179

47 Wang HK, Lin KH, Su SC, Shih TT, Huang YC. Effects of tendon viscoelasticity in Achilles tendinosis on explosive performance and clinical severity in athletes. Scand J Med Sci Sports 2012; 22: e147-e155

48 Weerapong P, Hume PA, Kolt GS. The mechanisms of massage and effects on performance, muscle recovery and injury prevention. Sports Med 2005; 35: 235-256

49 White KE. High hamstring tendinopathy in 3 female long distance runners. J Chiropr Med 2011; 10: 93-99

50 Winter D. Biomechanics and motor control of human movement. New York, NY: John Wiley \& Sons Inc., 1990

51 Zainuddin Z, Newton M, Sacco P, Nosaka K. Effects of massage on delayed-onset muscle soreness, swelling, and recovery of muscle function. J Athl Train 2005; 40: 174-180 